\title{
The Physiology of Riboflavin Production by Eremothecium ashbyi
}

\author{
BY F. KAPRALEK \\ Department of Microbiology, Charles University, Viničná 5, Prague 2 \\ Czechoslovakia
}

(Received 8 December 1961)

\begin{abstract}
SUMMARY
During the submerged batch cultivation of a riboflavin-producing strain of Eremothecium ashbyi three phases were observed. The first phase was characterized by rapid growth of mycelium, rapid utilization and oxidation of glucose and a decrease of $\mathrm{pH}$ value caused by accumulation of pyruvic acid. Subsequently acetoin accumulated in the medium. Glucose was oxidized incompletely since only $1 \cdot 8 \mu$ mole oxygen were consumed $/ \mu \mathrm{mole}$ glucose utilized. The end of this phase was marked by exhaustion of glucose and cessation of growth. The second phase began with sporulation and was characterized by rapid synthesis of cell-bound riboflavin. Simultaneously a rapid increase in catalase activity and decreases of pyruvate and acetoin were observed. This was accompanied by a marked decrease in $Q_{\mathrm{o}_{2}}$ on glucose while the $Q_{\mathrm{o}_{2}}$ on pyruvate, threonine or acetaldehyde increased to a maximum. Ammonia accumulated in the medium and alkaline $\mathrm{pH}$ values were reached. The third phase was characterized by autolysis of mycelium which led to the release of riboflavin and to a decrease of enzymic activities. A comparison of all important physiological parameters was made with two strains of $\boldsymbol{E}$. ashby $i$ of different riboflavin productivity. On the basis of correlation between riboflavin formation, catalase activity and respiration on acetaldehyde, an hypothesis is proposed to explain overproduction of riboflavin by a shift from the initial cytochrome type of terminal respiration to the flavoprotein type which is, however, accompanied by over-production of the flavin prosthetic group.
\end{abstract}

\section{INTRODUCTION}

Although much work has been done in studying the mechanism of biogensis of riboflavin (e.g. MacLaren, 1952; Goodwin \& Pendlington, 1954; McNutt, 1954; Plaut, 1954 $a, b$; Klugsøyr, 1954; Brown, Goodwin \& Pendlington, 1955; Goodwin \& Jones, 1956; Goodwin \& Treble, 1958; Brown, Goodwin \& Jones, 1958; Goodwin \& Horton, 1960; Katagiri \& Imai, 1961) and in examining the nutritional requirements of Eremothecium ashbyi (e.g. Schopfer, 1944; Dulaney \& Grutter, 1950; Yaw, 1952; Hickey, 1953; Dikanskaya, 1953) little attention has been paid to the physiology of this organism in connexion with riboflavin production. Dikanskaya (1954) found that, under stationary conditions of batch cultivation, in the first days of growth the mycelium was characterized by high respiratory activity and contained cytochromes. When riboflavin biosynthesis began the respiratory activity decreased and the cytochromes disappeared. A strain not producing riboflavin had greater respiratory activity than a producing strain; this difference increased during further 
cultivation. The cytochrome system was more active in the non-producing strain than in the producing one. Kramli \& Szabo (1956) found that during the submerged growth of $\boldsymbol{E}$. ashbyi the oxidation reduction potential first decreased and later returned slowly to the initial value when riboflavin was synthesized. Holló, Szamel, Nyeste \& Tegerdy (1956) described a characteristic $\mathrm{pH}$ curve; after a slight decrease on the first day of cultivation the $\mathrm{pH}$ rose to about 8 . Synthesis of riboflavin began later than growth and the maximal yield of riboflavin was obtained after 6-7 days of incubation.

In the mycelium of Eremothecium ashbyi Shimizu, Ohara \& Minoura (1952) found not only free riboflavin but also flavin mononucleotide (FMN) and flavin-adenine dinucleotide (FAD); this observation was confirmed by Stárka (1957). Yagi, Matsuoka, Kuyama \& Tada (1956) reported that during the early period of riboflavin production half of the mycelial riboflavin was present as FAD; later FAD was found also in medium. These authors worked out a procedure for preparation of the dinucleotide FAD from $\boldsymbol{E}$. ashbyi.

Dr A. Barth (personal communication, 1959) found that Eremothecium ashbyi contained both acid and alkaline phosphatases. While the acid phosphatase had maximum activity during growth, the alkaline phosphatase reached its maximum during riboflavin biosynthesis. The activity curve of acid phosphatase was roughly parallel to the growth curve, while the activity curve of alkaline phosphatase was parallel to the riboflavin formation curve. The specific roles of these enzymes is yet to be considered. On the basis of nutritional studies Dikanskaya (1953) pointed out that growth and riboflavin production were in some sense antagonistic processes: factors which favoured growth retarded riboflavin biosynthesis and vice versa. The same conclusion had already been reached by Schopfer (1944). No attempt was made to elucidate the physiological mechanism of riboflavin over-production by Eremothecium ashbyi, i.e. to find why this organism produces such great amounts of this physiologically-active compound. This is the purpose of present paper. Results of our preliminary experiments were published earlier, (Kaprálek, 1957).

\section{METHODS}

\section{Organism}

Most experiments were carried out with Eremothecium ashbyi strain ZA originating from the collection of the Department of Microbiology, Charles University, Prague. For the comparative experiment $E$. ashbyi strain AV was also used; this was derived from a strain from the Centraalbureau voor Schimmelcultures (Baarn, Netherlands) and produces greater amounts of riboflavin.

\section{Growth}

Both strains were maintained on medium A (see below) solidified with agar, 20 g. $/$ l. A $500 \mathrm{ml}$. flask with $50 \mathrm{ml}$. medium A was inoculated from an agar slope. After incubation at $28-30^{\circ}$ for 3-5 days on a reciprocal shaker (105 mm. stroke, 96 strokes/min.), $10 \mathrm{ml}$. of culture were inoculated into a $10 \mathrm{l}$. flask containing $1000 \mathrm{ml}$. medium A. This experimental flask was provided with a device for removing samples of culture aseptically during growth which was performed on a reciprocal shaker (50 mm. stroke, 84 strokes $/ \mathrm{min}$.) at $\mathbf{2 8 - 3 0 ^ { \circ }}$. After the experiment was 
finished the volume of culture was not less than $70 \%$ of the original volume. In control experiments it was found that this decrease of volume had no significant influence on the physiological parameters. Medium $A$ (MacLaren, 1952): glucose, 10 g.; peptone, 10 g.; yeast extract, 1 g.; distilled water to $1000 \mathrm{ml}$; pH 6.8 before sterilization for $20 \mathrm{~min}$. at $127^{\circ}$.

\section{Manometric methods}

The rates of $\mathrm{O}_{2}$ uptake and $\mathrm{CO}_{2}$ production were measured in the Warburg apparatus by the direct methods of Warburg at $28^{\circ}$ with air as the gas phase; the respective rates are expressed as $Q_{\mathrm{o}_{2}}$ and $Q_{\mathrm{Co}_{2}}, \mu \mathrm{l}$. gas $/ \mathrm{mg}$. mycelial dry wt./hr. The contents of Warburg vessels will be described later.

\section{Analytical methods}

Dry weight of mycelium was estimated by filtration of the culture suspension and drying the washed mycelium at $80^{\circ}$ for $24 \mathrm{hr}$. before weighing.

Riboflavin was determined fluorimetrically on a Klett objective fluorimeter by use of a calibration curve. The total riboflavin content was measured as follows. Two ml. of culture suspension $+8 \mathrm{ml} .0 .02 \mathrm{~N}-\mathrm{HCl}$ were autoclaved for $20 \mathrm{~min}$. at $120^{\circ}$; the supernatant fluid was diluted and assayed fluorimetrically. Riboflavin in the medium was determined as follows. Two ml. of culture filtrate $+8 \mathrm{ml} .0 \cdot 02 \mathrm{~N}-\mathrm{HCl}$ were autoclaved for $20 \mathrm{~min}$. at $120^{\circ}$; the supernatant fluid was diluted and analysed. The relatively high concentration of riboflavin made it possible to use large dilutions so that the nonspecific fluorescence was eliminated.

pH measurements were made with a Philips pH-meter GM 4491 with quinhydrone and antimony electrodes and a saturated calomel electrode.

Oxidation-reduction potential was measured directly in the growing culture. A bright platinum electrode was installed through the cottonwool stopper of the experimental flask together with a bridge of saturated $\mathrm{KCl}$ solution in which the saturated calomel electrode was submerged after sterilization.

Paper chromatography. The lower fatty acids were separated according to the method of Brown \& Hall (1950) in a mixture of $n$-butanol $+1.5 \mathrm{~N}-\mathrm{NH}_{4} \mathrm{OH}(1+1$ by vol.) on Whatman no. 4 paper. The keto acids were separated as 2,4-dinitrophenylhydrazones (Cavallini \& Frontali, 1954) in a mixture of $n$-butanol + ethanol + water $(4+1+5$ by vol.) on Whatman no. 4 paper.

Pyruvic acid was determined by the method of Friedeman (1957). The sample was incubated with the 2,4-dinitrophenylhydrazine at $25^{\circ}$ for $25 \mathrm{~min}$. In the control analyses benzene ( $5 \mathrm{~min}$.) and butanol (25 $\mathrm{min}$.) were used.

Glucose. Analyses were made according to the method of Nelson (Ashwell, 1957).

Acetoin was determined by Westerfeld's method (Krampitz, 1957).

Ammonia was estimated according to the Conway diffusion method with Nesslerization.

The activity of deaminases was measured according to Boyd \& Lichstein (1953). The reaction tube contained $2 \mathrm{ml}$. $0.06 \mathrm{M}$-solution of substrate, $2 \mathrm{ml}$. of $0.05 \mathrm{M}$ phosphate buffer ( $\mathrm{pH} \mathbf{7 \cdot 0}$ ) and $1 \mathrm{ml}$. mycelium suspension disintegrated by freezing and thawing. After $1 \mathrm{hr}$. at $37^{\circ} 1 \mathrm{ml}$. of trichloroacetic acid $(200 \mathrm{~g} . / \mathrm{l}$.) solution was added, the mixture centrifuged and the supernatant fluid analysed for ammonia. 
The activity was expressed as $\mu$ mole ammonia liberated by equiv. $1 \mathrm{mg}$. dry wt. mycelium $/ \mathrm{hr}$.

Cytochrome oxidase activity was determined manometrically (Schneider \& Potter, 1943): $1 \mathrm{ml} .2 \cdot 3 \times 10^{-4} \mathrm{M}$-solution of cytochrome $c, 0 \cdot 3 \mathrm{ml} .4 \times 10^{-3} \mathrm{M}_{-} \mathrm{AlCl}_{3}, 1 \mathrm{ml}$. 0.1 M-phosphate buffer ( $\mathrm{pH} \mathbf{7 \cdot 4}$ ) and $0 \cdot 4 \mathrm{ml}$. of cell-free extract of Eremothecium ashbyi was put in the Warburg vessel. In the side arm $0.3 \mathrm{ml}$. $0.114 \mathrm{M}$-ascorbic acid (adjusted to $\mathrm{pH} 7$ ) and in central well $0.2 \mathrm{ml}$. KOH solution (200 g./1.) was placed. The activity of cytochrome oxidase is expressed as $\mu$ l oxygen consumed/ $\mathrm{hr}$./mg. protein, i.e. $Q_{\mathrm{o}_{2}}$ (protein).

The catalase activity was measured iodometrically (Avi-Dor \& Yaniv, 1952; Sumner, 1941): $1 \mathrm{ml}$. washed mycelial suspension (or $1 \mathrm{ml}$. mycelium suspension disintegrated by freezing and thawing, or $1 \mathrm{ml}$. cell-free extract, or $1 \mathrm{ml}$. of culture filtrate) was added to a flask containing $50 \mathrm{ml}$. of $0.01 \mathrm{~N}-\mathrm{H}_{2} \mathrm{O}_{2}$ in $0.015 \mathrm{M}$-phosphate buffer (pH 6.8) at $0^{\circ}$. After 3, 6, 9 and $12 \mathrm{~min} .5 \mathrm{ml}$. samples of this suspension were withdrawn and the residual $\mathrm{H}_{2} \mathrm{O}_{2}$ assayed iodometrically. The velocity constant was determined for each analysis according to the equation $k=\frac{2 \cdot 3}{t} \log _{10} \frac{a}{a-x}$, where $a$ is the initial $\mathrm{H}_{2} \mathrm{O}_{2}$ concentration and $x$ is the amount of $\mathrm{H}_{2} \mathrm{O}_{2}$ decomposed in $t$ sec. The value of $k_{0}$ was graphically extrapolated for $t_{0}$, and a correction for amount of enzyme preparation was used, i.e. the result was divided by $\frac{y}{51}$, where $y=\mathrm{mg}$. dry wt. mycelium, or mg. protein of cell-free extract, or ml. culture filtrate. This corrected value of $k_{0}$ was the measure of catalase activity.

Protein in cell-free extracts was determined by the method of Lowry, Rosebrough Farr \& Randall, (1951).

Cell-free extracts from mycelium of Eremothecium ashbyi were prepared by grinding several ml. of frozen thick mycelial suspension with powdered glass. After centrifugation at $1600 \mathrm{~g}$ for 10 mins. the supernatant fluid was used. All operations were done at temperatures not exceeding $5^{\circ}$.

Disintegration of mycelium by freezing and tharwing. Several $\mathrm{ml}$. of washed suspension (of known dry weight) were submerged in a bath cooled to $-70^{\circ}$. After a few minutes the frozen sample was thawed in a water bath at $20^{\circ}$. This procedure was repeated three times. The concentration is expressed as mg. dry wt. original mycelium suspension $/ \mathrm{ml}$. This operation led to the complete loss of viability and respiratory activity, indicating complete disintegration of mycelium.

\section{RESULTS}

Figure 1 shows the growth and production of riboflavin during submerged batch cultivation. Three phases can be distinguished. The 'phase of growth' was characterized by mycelial synthesis. After growth ceased the culture entered the 'phase of production' in which riboflavin was produced, most of it being in the mycelium. The 'phase of autolysis' was characterized by absence of further riboflavin production, by decrease of mycelial dry weight, and by release of riboflavin into the medium. The boundaries between phases were, of course, not sharp, but for description a simplification may be made; the phases are marked off with interrupted lines (Fig. 1). This overall picture of growth and riboflavin production was accom- 
panied by other characteristic changes. The oxidation reduction potential (Fig. 2) decreased rapidly during the lag phase from the initial value of about $0 \mathrm{mV}$ down to $-120 \mathrm{mV}$ where it remained during growth. In the phase of production the curve rose to $-\mathbf{3 0} \mathrm{mV}$ but in the phase of autolysis practically no change was observed. The $\mathrm{pH}$ curve (Fig. 2) shows that during growth acid was formed, with a decrease to $\mathrm{pH}$ 4. This acid disappeared during the phase of riboflavin production and subsequently the culture became alkaline, reaching $\mathrm{pH} 8$, which was higher than the initial value. During autolysis there were usually no changes in $\mathrm{pH}$ value; in a few instances the alkalinity increased slightly.

The acid produced was identified by paper chromatography. In the filtrate of $24 \mathrm{hr}$. cultures much pyruvic acid was found; in older cultures there were only

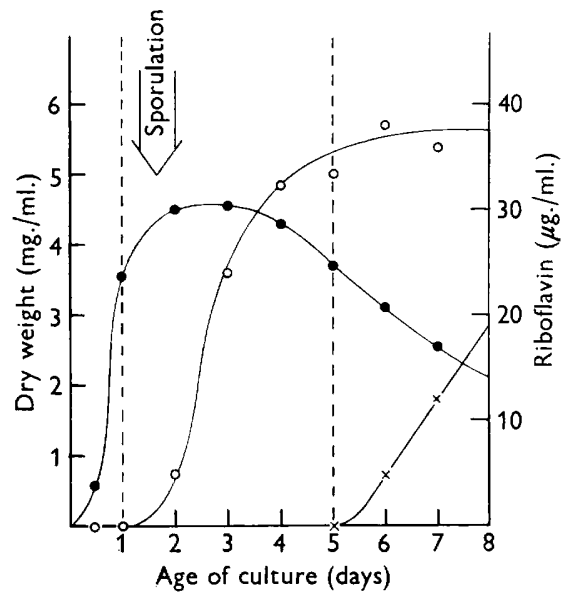

Fig. 1

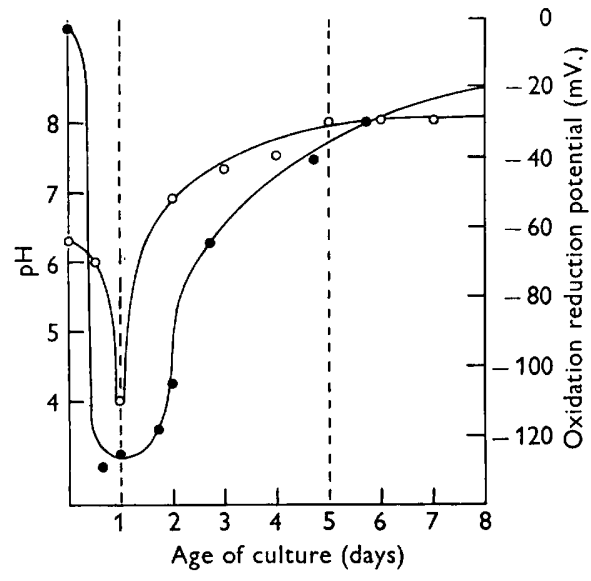

Fig. 2

Fig. 1. Growth and riboflavin production curves of Eremothecium ashbyi grown in submerged conditions on glucose-peptone-yeast extract medium. $0-\ldots$, total riboflavin; $\times-\times$, free riboflavin in medium.

Fig. 2. Changes in $\mathrm{pH}$ and oxidation-reduction potential during growth. $\bigcirc-O$, $\mathrm{pH} ;-$, oxidation-reduction potential.

traces of pyruvic acid. No $\alpha$-ketoglutaric acid nor other keto acid was found. These observations were confirmed by analytical methods. Lower fatty acids were not detected by chromatography during growth. Thus the acidity was due only to pyruvic acid. Pyruvic acid accumulated in the medium during the phase of growth and its amount quickly decreased during the production of riboflavin (Fig. 3).

The alkalinity was thought to be due to ammonia arising from the deamination of amino acids of the peptone. Although the concentration of ammonia was low and constant during the phase of growth, a considerable amount went into the medium at the beginning of the phase of production. In the third phase the ammonia concentration increased slightly because of autolysis (Fig. 3). Ammonia liberation into the medium at the beginning of the phase of production was caused by exhaustion of glucose (Fig. 4) since this led to the use of peptone as source of carbon and energy for the growth still perceptible at this stage (Fig. 1). From Figs. 3 and 4 it can be concluded that during the phase of growth the culture dissimilated glucose 
quickly but not completely, because from $56 \mu$ mole glucose utilized about $25 \mu$ mole pyruvic acid were formed i.e. about $25 \%$ of utilized glucose accumulated as pyruvic acid. Further oxidation of pyruvic acid was evidently a limiting step in the glucose dissimilation during the phase of growth. A small amount of acetoin also accumulated in the medium (Fig. 4). During further incubation the concentration of pyruvate and acetoin decreased. It seems that during the first two phases the culture was using two different sources of energy and carbon, i.e. glucose in the phase of growth and pyruvic acid in the phase of production.

The catalase activity during incubation was determined since flavin-containing oxidases, supposed to be present during the phase of production, are physiologically coupled with this enzyme. Catalase activity was not detected during the phase of

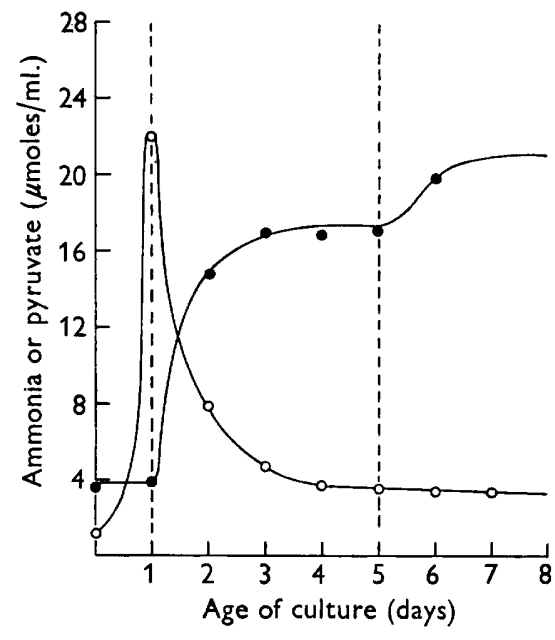

Fig. 3

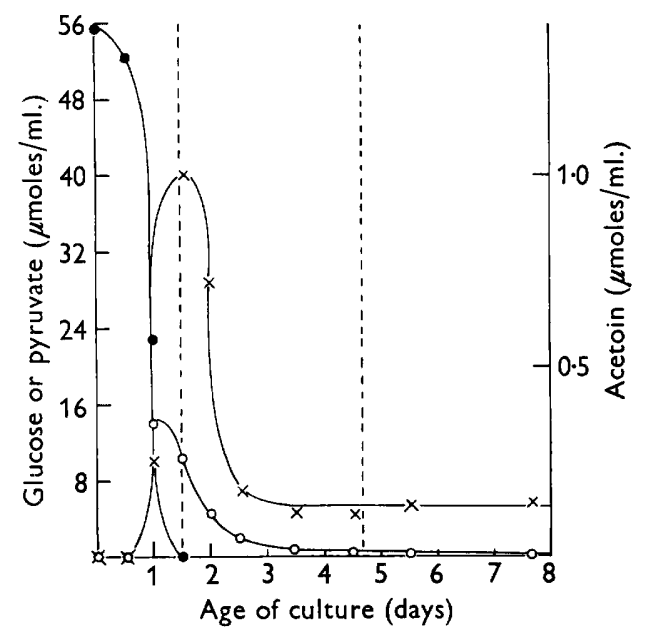

Fig. 4

Fig. 3. The levels of ammonia and pyruvate in the medium during growth. Ammonia; $\mathrm{O}-\mathrm{O}$, pyruvate.

Fig. 4. The levels of glucose, pyruvate and acetoin in the medium during growth. -0 , Glucose; $O \longleftarrow 0$, pyruvate; $\times \longrightarrow \times$, acetoin.

growth (Fig. 5). In the phase of production catalase activity increased rapidly, together with riboflavin synthesis. There followed a decrease of catalase activity which was typical for the phase of autolysis. Possible effects of permeability factors in this phenomenon were eliminated by using not only intact mycelium but also mycelium disintegrated by freezing and thawing, and a cell-free extract (Fig. 6). The activity of cytochrome oxidase was determined with the cell-free extract (Fig. 6) and the deaminase activities by using disintegrated mycelium (Fig. 7). The deaminase activities for asparagine and serine were consistent with our previous explanation (p. 407) of the alkalization of the medium by ammonia at the beginning of the phase of production.

The respiratory activity of samples of washed mycelium on selected substrates taken during incubation was studied. Warburg vessels contained $1 \mathrm{ml} . \mathbf{0 \cdot 3} \mathrm{M}$ phosphate buffer $(\mathrm{pH} \mathrm{6.5}), 1 \mathrm{ml}$. $0.06 \mathrm{M}$-substrate, $1 \mathrm{ml}$. suspension of washed mycelium and in centre well $0.2 \mathrm{ml}$. KOH solution $(200 \mathrm{~g} . / 1$.). The results are 


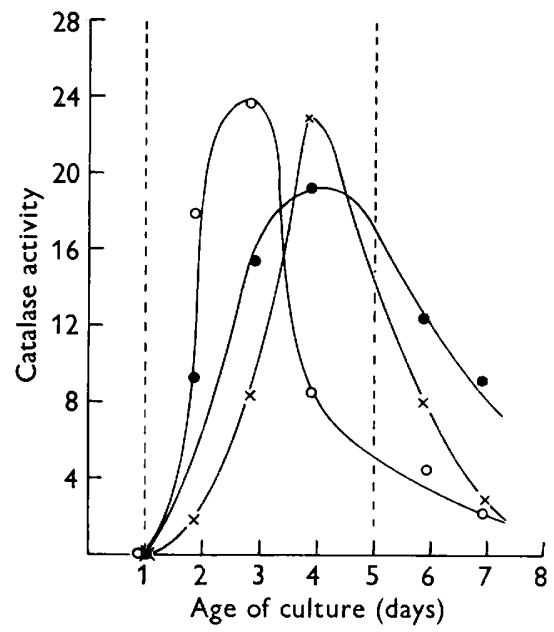

Fig. 5

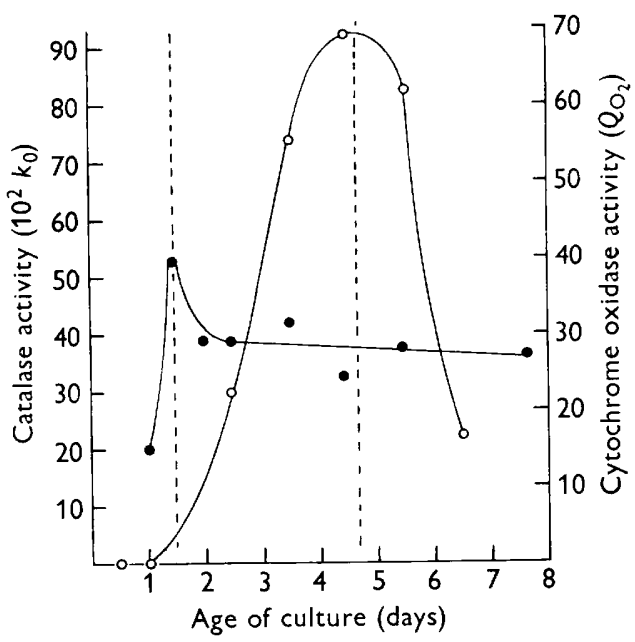

Fig. 6

Fig. 5. The activity of catalase during growth.

, Washed intact mycelium $\left(10^{3} k_{0}\right) ; \bigcirc-O$, mycelium disintegrated by freezing and thawing $\left(10^{2} k_{0}\right) ; \times-\times$, the filtrate of the culture $\left(10^{4} k_{0}\right)$.

Fig. 6. The activity of catalase and cytochrome oxidase during growth (cell-free extract). $\mathrm{O}-\mathrm{O}$, Catalase; , cytochrome oxidase.

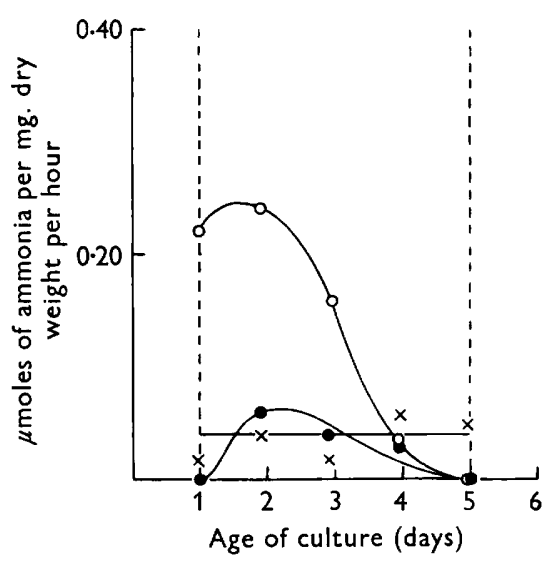

Fig. 7

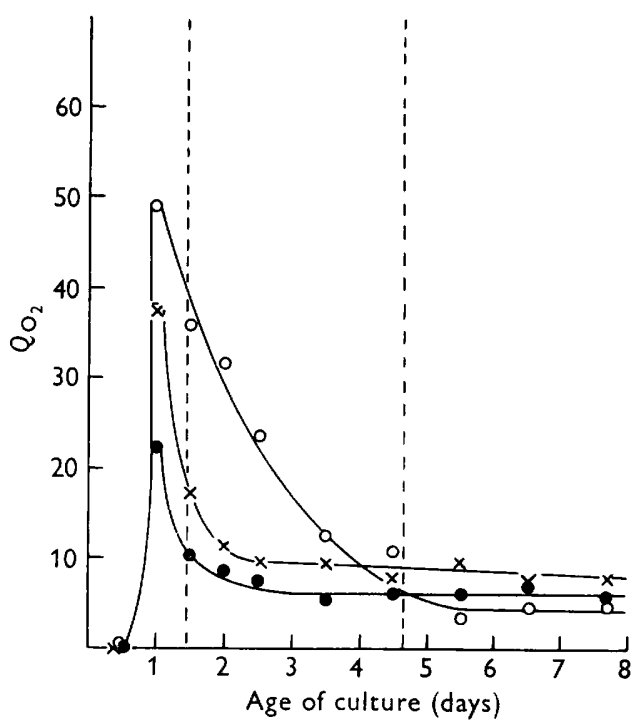

Fig. 8

Fig. 7. The activity of deaminases during growth (mycelium disintegrated by freezing and thawing). $\mathrm{O}-\mathrm{O}, \mathrm{L}$-asparagine;

Fig. 8. The respiratory activity of washed mycelium on glucose and acetate (values are corrected for endogenous respiration); - - Endogenous respiration; $O-O$, glucose; $\times-\times$, acetate. 
illustrated in Figs. 8, 9 and 10 (values corrected for endogenous respiration). The substrates can be divided into two groups. The first group (glucose, acetate, peptone, DL-serine, L-asparagine; with L-arginine, L-glutamic acid, DL-alanine, vitamin-free casamino acids, in preliminary experiments) showed maximum respiratory activity at the end of the phase of growth. During the phase of production the activity decreased and a low and constant respiration persisted in the phase of autolysis. The second group of substrates (L-threonine, acetaldehyde, pyruvate) had a very low or zero rate of oxidation during the phase of growth. On passing into the phase of production the $Q_{\mathrm{O}_{2}}$ began to rise and reached a peak during production. L-Leucine, L-histidine, glycine, DL-methionine and L-aspartic acid were not oxidized.

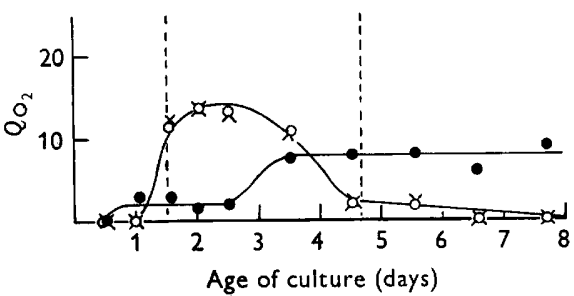

Fig. 9

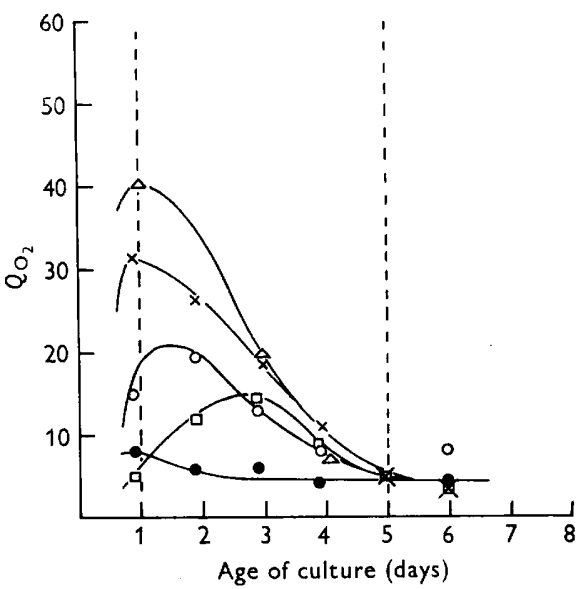

Fig. 10

Fig. 9. The respiratory activity of washed mycelium on pyruvate, L-threonine and acetaldehyde (values are corrected for endogenous respiration which is the same as in Fig. 8). -, Pyruvate; $\mathrm{O}-\mathrm{O}$, L-threonine; $\times-\times$, acetaldehyde.

Fig. 10. The respiratory activity of washed mycelium on L-asparagine, DL-serine, peptone and L-threonine (values are corrected for endogenous respiration).

Endogenous respiration; $O \longrightarrow O$, L-asparagine; $\times \longrightarrow \times$, oL-serine; $\triangle \longrightarrow \triangle$, peptone; $\square \longrightarrow \square$, L-threonine.

The respiratory activity of the whole culture during incubation was also determined by removing $3 \mathrm{ml}$. samples of culture and immediately measuring $Q_{\mathrm{O}_{2}}$, $\boldsymbol{Q}_{\mathrm{OO}_{2}}$ and R.Q. in Warburg vessels. From Fig. 11 it is clear that the phase of growth was characterized by high initial values of R.Q., $Q_{\mathrm{O}_{2}}$ and $Q_{\mathrm{CO}_{2}}$ all of which rapidly decreased. During the phase of production the R.Q. curve increased from $0 \cdot 6$ to $0 \cdot 9$, and the rapid decrease in $Q_{\mathrm{O}_{2}}$ and $Q_{\mathrm{CO}_{2}}$ was interrupted. In the phase of autolysis the decrease of $Q_{\mathrm{O}_{2}}$ and $Q_{\mathrm{CO}_{2}}$ continued while the R.Q. value was constant and near to $1 \cdot 0$.

In subsequent experiments the quantitative aspects of oxidation of glucose and pyruvate by 1 day mycelium (phase of growth) and 3 day mycelium (phase of production) were studied. By the direct Warburg method the amounts of $\mathrm{O}_{2}$ consumed and $\mathrm{CO}_{2}$ produced per unit of substrate utilized at various concentrations of substrates were determined. At the end of the experiment $1 \mathrm{ml}$. of $5 \%$ $(\mathrm{w} / \mathrm{v})$ trichloroacetic acid as added to the Warburg vessel and after centrifugation 
the supernatant fluid was analysed for glucose and pyruvate. From Figs. 12 and 13 and Tables 1 and 2 the following conclusions may be drawn for the mycelium from the phase of growth (values of endogenous respiration substracted). The R.Q. value of endogenous respiration was near to 1 , suggesting that the endogenous material oxidized was carbohydrate. Glucose was not completely oxidized; about $1 \cdot 8 \mu$ mole oxygen was consumed $/ \mu$ mole glucose. The R.Q. for glucose (20 and $60 \mu \mathrm{mole} / \mathrm{vessel}$ )

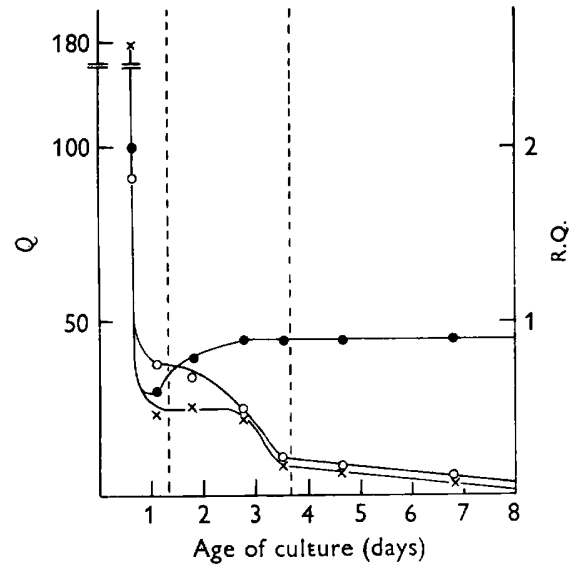

Fig. 11

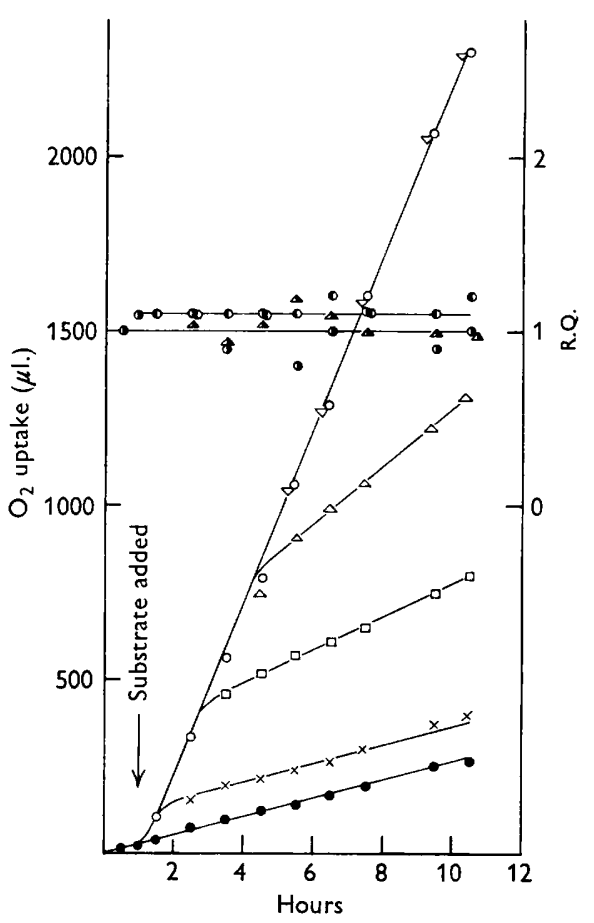

Fig. 12

Fig. 11. The respiratory activity of the whole culture during cultivation.

$\mathrm{O}-\mathrm{O}, \boldsymbol{Q}_{\mathrm{O}_{\mathbf{2}}} ; \times-\times, \boldsymbol{Q}_{\mathrm{CO}_{2}}$.

Fig. 12. Oxidation of glucose by 1 day-old washed mycelium. Warburg vessels contained: $1 \mathrm{ml}$ of solution of substrate of concentration noted, $1 \mathrm{ml} 0.3 \mathrm{M}$-phosphate buffer pH 6.5 and $1 \mathrm{ml}$ of washed mycelium (4.81 mg dry weight) suspended in $0.8 \%$ (w/v) solution of $\mathrm{NaCl}$. For $\mathrm{CO}_{2}$ absorption $0 \cdot 2 \mathrm{ml}$ of $20 \%(\mathrm{w} / \mathrm{v}) \mathrm{KOH}$ was added to the central well. The R.Q. value was determined for each interval separately.

Endogenous respiration; $x-\times$, glucose $2 \mu \mathrm{mole} / \mathrm{ml} ; \square-\square$, glucose $10 \mu \mathrm{mole} / \mathrm{ml}$; $\triangle \longrightarrow \triangle$, glucose $20 \mu \mathrm{mole} / \mathrm{ml} ; \nabla-\nabla$, glucose $60 \mu \mathrm{mole} / \mathrm{ml} ; \bigcirc-0$, glucose $100 \mu \mathrm{mole} / \mathrm{ml}$; - R.Q. for endogenous respiration; $\Delta-\Delta, \mathbf{A} . \mathbf{Q}$. for glucose $20 \mu \mathrm{mole} / \mathrm{ml}$; - D , R.Q. for glucose $60 \mu \mathrm{mole} / \mathrm{ml}$.

was near to 1. After the glucose (10 and $20 \mu \mathrm{mole} / \mathrm{vessel}$ ) was exhausted the curve was not parallel to the endogenous respiration. The possibility exists that a labile endogenous material (pyruvic acid) was made from glucose. This material may then be oxidized very slowly or it may stimulate the endogenous respiration (see below). This would agree with the observation that the endogenous respiration of 1 day mycelium (when glucose is still present in the medium) was greater than that of older mycelium (Figs. 8 and 10). 
Pyruvate was oxidized only very slowly, but its concentration decreased more rapidly, suggesting metabolic activity (intracellular accumulation) without $\mathrm{O}_{2}$ consumption or $\mathrm{CO}_{2}$ production. The possibility cannot be excluded that pyruvate is not oxidized at all but causes stimulation of endogenous respiration.

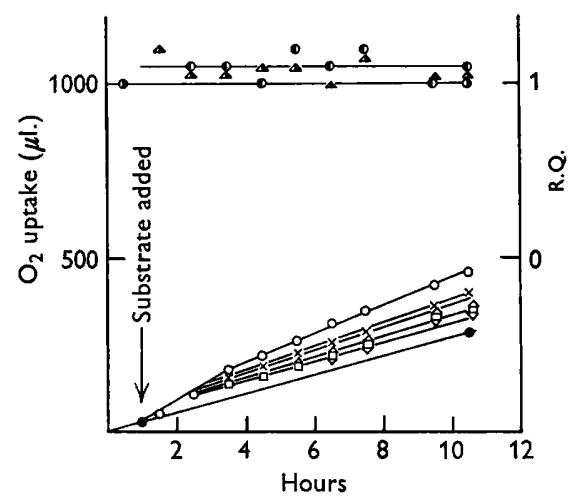

Fig. 13

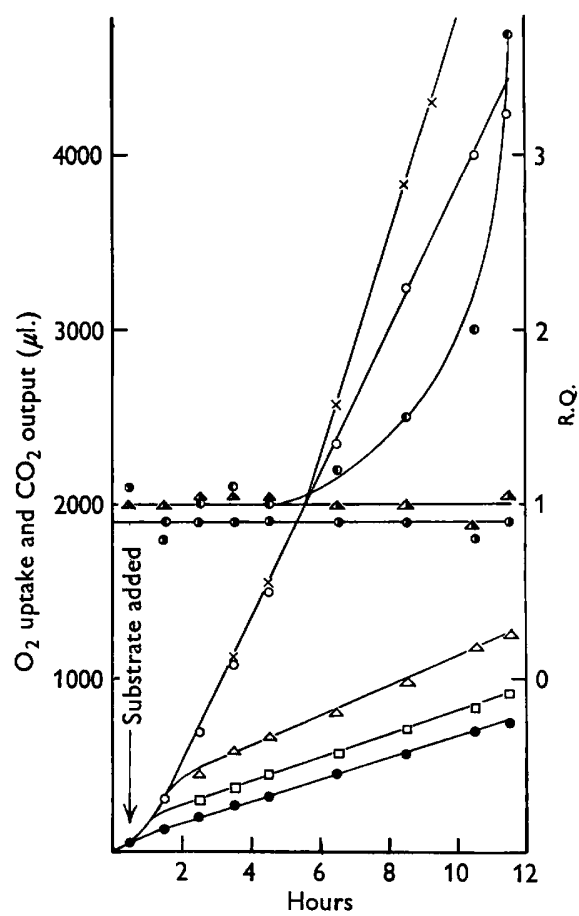

Fig. 14

Fig. 13. Pyruvate oxidation by 1 day-old washed mycelium. The contents of Warburg vessels are the same as in Fig. 12. The R.Q. value was determined for each interval separately. - - , Endogenous respiration (the same as in Fig. 12); $\nabla-\nabla$, pyruvate $40 \mu \mathrm{mole} / \mathrm{ml} ; \square-\square$, pyruvate $60 \mu \mathrm{mole} / \mathrm{ml} ; \Delta-\Delta$, pyruvate $80 \mu \mathrm{mole} / \mathrm{ml}$; $\times \multimap \times$, pyruvate $100 \mu \mathrm{mole} / \mathrm{ml} ; \bigcirc-O$, pyruvate $150 \mu \mathrm{mole} / \mathrm{ml} ; 0-0$, R.Q. for endogenous respiration (the same as in Fig. 12); $\Delta-\Delta, \mathbf{A} . \mathrm{Q}$. for pyruvate $80 \mu \mathrm{mole} /$ $\mathrm{ml}$; - , R.Q. for pyruvate $150 \mu \mathrm{mole} / \mathrm{ml}$.

Fig. 14. Glucose oxidation by 3 days old washed mycelium. The contents of the Warburg vessels are the same as in Fig. 12 with the exception of mycelium concentration: 10.74 $\mathrm{mg} / \mathrm{ml}$. The R.Q. value was determined for each interval separately.

-10 , Endogenous respiration; $\square-\square$, glucose $5 \mu \mathrm{mole} / \mathrm{ml} ; \Delta \longrightarrow-\Delta$, glucose $10 \mu \mathrm{mole} / \mathrm{ml}$; $\bigcirc-O$, glucose $100 \mu \mathrm{mole} / \mathrm{ml}$; $-\mathrm{C}$, R.Q. for endogenous respiration; $\Delta-\Delta$, R.Q. for glucose $10 \mu \mathrm{mole} / \mathrm{ml}$; $C-D$, R.Q. for glucose $100 \mu \mathrm{mole} / \mathrm{ml} ; \times-\times$, $\mathrm{C}_{\mathrm{O}_{2}}$ production in $\mu \mathrm{l}$. on glucose $100 \mu \mathrm{mole} / \mathrm{ml}$.

From Figs. 14 and 15 and Tables 1 and 2 it is apparent that 3 day mycelium also oxidized glucose incompletely: about $1.8 \mu$ mole $\mathrm{O}_{2}$ was consumed $/ \mu$ mole glucose utilized. The R.Q. value was near to 1 , except with the high concentration of glucose (100 $\mu \mathrm{mole} / \mathrm{vessel})$. In this case a higher rate of $\mathrm{CO}_{2}$ production occurred at $4 \mathrm{hr}$., accompanied by an increase in R.Q. At the end of the experiment an excess of $87 \mu$ mole $\mathrm{CO}_{2}$ had been produced over that expected from the $\mathrm{O}_{2}$ consumption for an R.Q. of 1 . This phenomenon may be explained by anaerobic decarboxylation of the 
pyruvic acid arising from incomplete oxidation of glucose; $87 \mu$ mole $\mathrm{CO}_{2}$ corresponds to $87 \mu$ mole pyruvate decarboxylated, which corresponds to $43.5 \mu$ mole glucose. At the end of the experiment $\mathbf{1 . 2} \mu$ mole pyruvate was found. This means that

Table 1. Glucose oxidation by 1 day old and 3 days old washed mycelium (see Figs. 12 and 14)

\begin{tabular}{|c|c|c|c|c|c|}
\hline \multirow[b]{2}{*}{$\begin{array}{l}\text { Glucose } \\
\text { added } \\
\text { ( } \mu \mathrm{mole} / \\
\text { vessel) }\end{array}$} & \multicolumn{2}{|c|}{ At the end of experiment } & \multirow[b]{2}{*}{$\begin{array}{c}\text { Glucose } \\
\text { utilized } \\
(\mu \text { mole } / \\
\text { vessel })\end{array}$} & & \multirow{2}{*}{$\begin{array}{c}\text { Oxygen } \\
\text { consumed } \\
\text { ( } \mu \text { mole } / \\
\mu \text { mole } \\
\text { glucose } \\
\text { utilized) }\end{array}$} \\
\hline & $\begin{array}{l}\text { Glucose } \\
\text { found } \\
\text { ( } \mu \mathrm{mole} / \\
\text { vessel) }\end{array}$ & $\begin{array}{l}\text { Pyruvate } \\
\text { found } \\
\mu(\text { mole } / \\
\text { vessel })\end{array}$ & & $\begin{array}{c}\text { Oxygen } \\
\text { consumed } \\
(\mu \mathrm{moles}) *\end{array}$ & \\
\hline \multicolumn{6}{|c|}{1 day old mycelium } \\
\hline 2 & $0 \cdot 0$ & 0.0 & $2 \cdot 0$ & $4 \cdot 5$ & $\mathbf{2 \cdot 2}$ \\
\hline 10 & 0.7 & 0.0 & $9 \cdot 3$ & $16 \cdot 0$ & $1 \cdot 7$ \\
\hline 20 & $\mathbf{2 \cdot 0}$ & $0 \cdot 0$ & $18 \cdot 0$ & $31 \cdot 6$ & $1 \cdot 8$ \\
\hline 60 & $13 \cdot 3$ & $0 \cdot 2$ & $46 \cdot 7$ & $90 \cdot 9$ & $1 \cdot 9$ \\
\hline \multirow[t]{2}{*}{100} & $44 \cdot 1$ & 0.6 & $\mathbf{5 5 . 9}$ & $90 \cdot 9$ & $1 \cdot 6$ \\
\hline & \multicolumn{4}{|c|}{3 days old mycelium } & Mean $1 \cdot 8$ \\
\hline 5 & 0.2 & $0 \cdot 0$ & $4 \cdot 8$ & $7 \cdot 1$ & 1.5 \\
\hline 10 & 0.3 & $0 \cdot 0$ & $9 \cdot 7$ & $22 \cdot 8$ & $\mathbf{2} \cdot \mathbf{3}$ \\
\hline \multirow[t]{2}{*}{100} & $4 \cdot 3$ & $1 \cdot 2$ & $95 \cdot 7$ & $154 \cdot 0$ & $1 \cdot 6$ \\
\hline & & & & & Mean $1 \cdot 8$ \\
\hline
\end{tabular}

Table 2. Pyruvate oxidation by $\mathbf{1}$ day old and $\mathbf{3}$ days old washed mycelium (see Figs. 13 and 15)

\begin{tabular}{|c|c|c|c|c|}
\hline $\begin{array}{c}\text { Pyruvate } \\
\text { added } \\
(\mu \mathrm{mole} / \mathrm{vessel})\end{array}$ & $\begin{array}{c}\text { Residual } \\
\text { pyruvate } \\
(\mu \text { mole/vessel })\end{array}$ & $\begin{array}{c}\text { Pyruvate } \\
\text { utilized } \\
(\mu \text { mole/vessel })\end{array}$ & $\begin{array}{l}\text { Oxygen } \\
\text { consumed } \\
(\mu \text { moles })^{*}\end{array}$ & $\begin{array}{c}\text { Oxygen } \\
\text { consumed } \\
(\mu \mathrm{mole} / \mu \mathrm{mole} \\
\text { pyruvate } \\
\text { utilized })\end{array}$ \\
\hline \multicolumn{5}{|c|}{1 day old mycelium } \\
\hline 40 & $13 \cdot 3$ & $26 \cdot 7$ & $2 \cdot 2$ & $0 \cdot 08$ \\
\hline 60 & 15.5 & $44 \cdot 5$ & $3 \cdot 8$ & 0.09 \\
\hline 80 & $30 \cdot 8$ & $49 \cdot 2$ & 4.9 & $0 \cdot 10$ \\
\hline 100 & $\mathbf{3 5 \cdot 9}$ & $64 \cdot 1$ & $6 \cdot 2$ & $0 \cdot 10$ \\
\hline \multirow[t]{3}{*}{150} & $56 \cdot 3$ & $93 \cdot 7$ & $8 \cdot 0$ & 0.09 \\
\hline & \multirow{2}{*}{\multicolumn{3}{|c|}{3 days old mycelium }} & Mean $0 \cdot 09$ \\
\hline & & & & \\
\hline 60 & $11 \cdot 3$ & $48 \cdot 7$ & $12 \cdot 5$ & $0 \cdot 26$ \\
\hline 80 & $12 \cdot 2$ & $67 \cdot 8$ & $20 \cdot 1$ & $0 \cdot 29$ \\
\hline \multirow[t]{2}{*}{150} & $24 \cdot 0$ & $126 \cdot 0$ & $40 \cdot 6$ & 0.32 \\
\hline & & & & Mean 0.29 \\
\hline
\end{tabular}

from $95 \mu$ mole glucose utilized at least $44 \mu$ mole $(46 \%)$ was transformed to pyruvate. The amount of pyruvate formed might be still greater since intracellular accumulation (see above) and the oxidation (see below) of pyruvic acid might also occur. 
The mycelium from 3 day cultures oxidized pyruvate, but very incompletely: about $0 \cdot 3 \mu$ mole $\mathrm{O}_{2}$ was consumed $/ \mu$ mole pyruvic acid utilized. The observed R.Q. $(\mathbf{1 \cdot 2})$ is the sum of R.Q.S of endogenous respiration (0.9) and of pyruvate oxidation. The R.Q. for pyruvate oxidation itself can be calculated according to the equation $0 \cdot 9 k_{1}+X k_{2}=1 \cdot 2\left(k_{1}+k_{2}\right.$ ) (where $k_{1}=$ rate of endogenous respiration, $k_{2}=$ rate of $\mathrm{O}_{2}$ consumption on pyruvate itself and $X=$ R.Q. for pyruvate oxidation). Substituting experimentally obtained values for $k_{1}$ and $k_{2}$ in this equation yields a value of 1.35 for the R.Q. of pyruvate oxidation. This is greater than the theoretical 1.2 and suggests anaerobic decarboxylation in addition to oxidation of pyruvate.

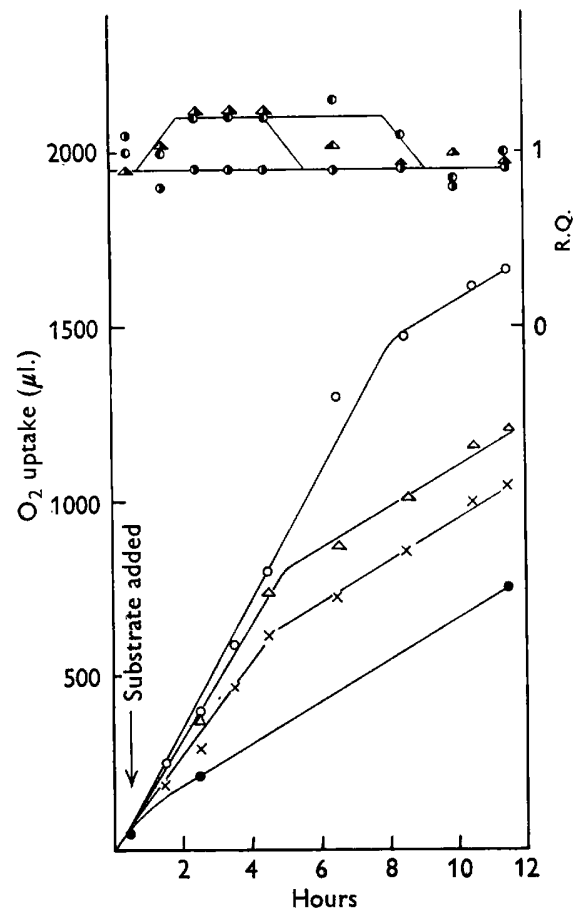

Fig. 15. Pyruvate oxidation by 3 days old washed mycelium. The contents of the Warburg vessels are the same as in Fig. 14. The R.Q. value was determined for each interval separately. - _ Endogenous respiration (the same as in Fig. 14); $\times-\ldots$, pyruvate $60 \mu \mathrm{mole} / \mathrm{ml} ; \triangle-\triangle$, pyruvate $80 \mu \mathrm{mole} / \mathrm{ml} ; 0-\bigcirc$, pyruvate $150 \mu$ mole $/ \mathrm{ml} ; \bigcirc-$, R.Q. for endogenous respiration (the same as in Fig. 14); $\Delta-\Delta$, R.Q. for pyruvate $80 \mu \mathrm{mole} / \mathrm{ml}$; $-\mathrm{O}$, R.Q. for pyruvate $150 \mu \mathrm{mole} / \mathrm{ml}$.

\section{Comparison of two strains of Eremothecium ashbyi}

All the important physiological parameters of the cultivation were compared for two strains: Eremothecium ashbyi strain $\mathbf{Z A}$ (with which all the hitherto described experiments were made) and $E$. ashbyi strain $\mathbf{A V}$, which produces three times as much riboflavin. The purpose of this comparison was to verify the interrelationships found by using another strain of $E$. ashbyi and to eliminate coincidental phenomena not related to riboflavin over-production and to $E$. ashbyi in general. The other question under study was the quantitative relationships between riboflavin production and other physiological processes. From the comparison it follows that the 
results reported here were valid for both strains, so that their pertinence for riboflavin production by $\boldsymbol{E}$. ashbyi is probably general. Both strains showed little significant difference in the physiological parameter except for riboflavin production and $Q_{0_{2}}$ on pyruvate (Fig. 16).

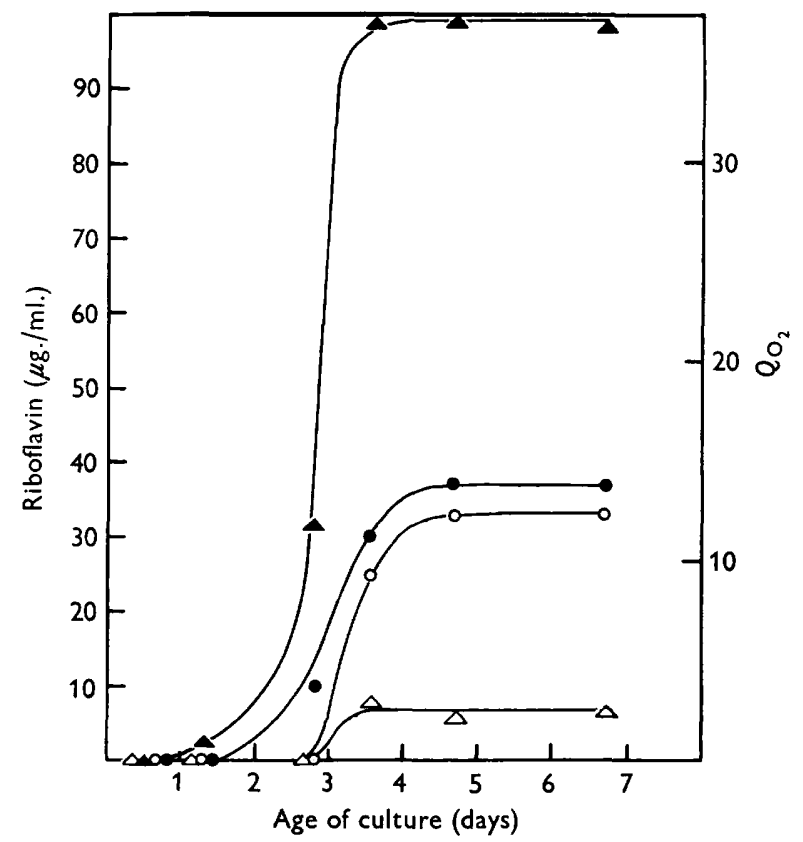

Fig. 16. Comparison of two strains of Eremothecium ashbyi of different riboflavin productivities. The lower producing strain E. ashbyi ZA: - - total riboflavin in $\mu \mathrm{g} / \mathrm{ml}$; $\bigcirc-O, Q_{0_{2}}$ on pyruvate. The higher producing strain $E$. ashbyi $\mathbf{A V}: \Delta-\Delta$, total riboflavin in $\mu \mathrm{g} / \mathrm{ml} ; \triangle \longrightarrow \triangle, \boldsymbol{Q}_{\mathrm{O}_{2}}$ on pyruvate. The values of $\boldsymbol{Q}_{\mathrm{O}_{2}}$ are corrected for endogenous respiration and are for washed mycelium.

\section{DISCUSSION}

It is apparent that the curves of growth, riboflavin production and $\mathrm{pH}$ values of culture differed markedly from those found under static conditions (Dikanskaya, 1954; Goodwin, 1959) not only in that all processes were more rapid in our submerged growth conditions but also that under static conditions no succession was found in the main phases-i.e. of growth, production and autolysis. Our curves of $\mathrm{pH}$ value, glucose and total riboflavin production may be compared with the results of Mickelson (1950) and Pfeifer, Tanner \& Traufler (1950) with submerged cultivation of Ashbya gossypii, an organism very closely related to Eremothecium ashbyi. The curves of riboflavin biosynthesis and $\mathrm{pH}$ changes are very similar to those found by Holló et al. (1956). In our experiments the curve of oxidation-reduction potential as found by Krámli \& Szabó (1956) was confirmed.

The most interesting observation seems to be that simultaneously with riboflavin production catalase activity appeared for the first time, although $80 \%$ of the mycelium had already been formed. This, together with the finding of Dikanskaya (1954) that the cytochromes of Eremothecium ashbyi disappeared during riboflavin production, suggests (Kaprálek, 1957) that riboflavin production is a consequence of 
a shift from the cytochrome type of terminal respiration to the flavoprotein type. The latter is physiologically coupled with catalase, but here a disorder in flavin oxidase activity leads to failure in regulation of flavin coenzyme synthesis.

The observations are consistent with this hypothesis. The physiological mechanism of riboflavin production by Eremothecium ashbyi may be pictured as follows. Until sporulation the culture grows normally and utilizes glucose (Figs. 1 and 4). Respiration proceeds by the cytochrome system (Dikanskaya, 1954; Fig. 6) but as an intermediate of glucose dissimilation, pyruvic acid, accumulates (Fig. 3), and causes a marked decrease in the $\mathrm{pH}$ value of the medium (Fig. 2). The further oxidation of pyruvate is apparently the limiting step in glucose oxidation (Figs. 9, 13; Table 2), i.e. the organism cannot oxidatively decarboxylate pyruvate to acetate, although it has a system for acetate oxidation (Fig. 8). The oxygen consumption of $1.8 \mu \mathrm{mole} / \mu \mathrm{mole}$ glucose utilized and the R.Q. of 1.0 (Fig. 12; Table 1) can be then explained only by supposing that the pentose cycle operates, allowing oxidation of glucose to $\mathrm{CO}_{2}$ and $\mathrm{H}_{2} \mathrm{O}$ by a mechanism alternative to glycolysis and the Krebs cycle. In the case of $E$. ashby $i$ the oxidation of glucose is incomplete and the sequence of reactions may be summarized as follows:

$$
\begin{aligned}
6 \text { hexose- } \mathrm{PO}_{4}+6 \mathrm{O}_{2}+6 \mathrm{H}_{2} \mathrm{O} & \rightarrow 6 \text { pentose- } \mathrm{PO}_{4}+6 \mathrm{CO}_{2}+12 \mathrm{H}_{2} \mathrm{O} \\
4 \text { pentose- } \mathrm{PO}_{4} & \rightarrow 2 \text { hexose- } \mathrm{PO}_{4}+2 \text { tetrose- } \mathrm{PO}_{4} \\
2 \text { pentose- } \mathrm{PO}_{4}+2 \text { tetrose- } \mathrm{PO}_{4} & \rightarrow 2 \text { hexose- } \mathrm{PO}_{4}+2 \text { triose- } \mathrm{PO}_{4} \\
2 \text { triose- } \mathrm{PO}_{4} & \rightarrow 2 \text { triose }+2 \mathrm{P}_{\text {in }} \\
2 \text { hexose- } \mathrm{PO}_{4}+6 \mathrm{O}_{2} & \rightarrow 6 \mathrm{CO}_{2}+6 \mathrm{H}_{2} \mathrm{O}+2 \mathrm{P}_{\text {in }}+2 \text { triose }
\end{aligned}
$$

The incompleteness of glucose oxidation may be caused by deficiency of aldolase which normally condenses two triose-phosphates to fructose-1-6-diphosphate, from which one phosphate group is split thus completing the cycle. The postulated deficiency of aldolase and the demonstrated low rate of pyruvate oxidation might be the cause of pyruvate accumulation in glucose dissimilation. The fact that the full theoretical amount of pyruvate was not found might be due to utilization of some pyruvate for biosynthesis of mycelium.

Later the cytochromes disappear (Dikanskaya, 1954) for reasons not yet known. Some connexion with sporulation or an effect of some metabolite may be involved. During utilization of peptone as a carbon and energy source the deaminase activities increase (Fig. 7) and ammonia accumulates (Fig. 3) causing the culture to become alkaline, $\mathrm{pH} \mathrm{7-8,} \mathrm{(Fig.} \mathrm{2).} \mathrm{At} \mathrm{the} \mathrm{same} \mathrm{time} \mathrm{biosynthesis} \mathrm{of} \mathrm{riboflavin} \mathrm{begins}$ (Fig. 1), catalase activity emerges (Fig. 5) and the amount of pyruvic acid decreases (Fig. 3). The $Q_{\mathrm{O}_{2}}$ on glucose is decreased (Fig. 8) while on the other hand the $Q_{\mathrm{O}_{2}}$ on pyruvate, threonine and acetaldehyde increases (Fig. 9). The riboflavin formed is bound in the cells (Fig. 1) and much is present as FAD (Yagi et al. 1956).

These facts could be explained by the appearance of a new enzyme of inducible character, a flavoprotein which reacts directly with oxygen, producing $\mathrm{H}_{2} \mathrm{O}_{2}$ which is decomposed by catalase. This new enzyme may be involved in the oxidation not

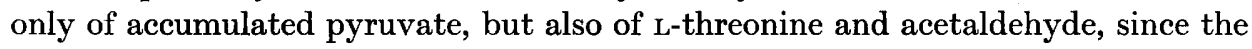
maximum $Q_{\mathrm{O}_{2}}$ values of these all lie in the phase of production. The common denominator of these three substrates is acetaldehyde, which arises from pyruvic acid by decarboxylation and from threonine by the action of threonine aldolase. 
The presence of both processes in Eremothecium ashbyi was shown by Goodwin \& Horton (1960) who pointed out that L-threonine specifically stimulated the biosynthesis of riboflavin. We may therefore conclude that the inducible flavoprotein is an aldehyde oxidase. The well-known aldehyde oxidase contains FAD as coenzyme, has an optimum at $\mathrm{pH} \mathrm{7-8}$ and oxidizes aldehydes to the corresponding acids (in particular acetaldehyde to acetate which is further oxidized) (Fig. 8). This type of respiration is thus used by the organism after the loss of the cytochrome system.

However, the regulation of FAD synthesis breaks down for reasons not yet known and this is the ultimate cause of riboflavin over-production. Perhaps a system is present which continually splits off the prosthetic group of the flavoprotein and this leads to compensation in the form of increased FAD synthesis. The greater this disorder, the lower is the respiratory activity on pyruvate during the phase of production and the greater is the riboflavin over-production (Fig. 16). The opinion that there exists a reserve type of respiration is supported by the results shown in Fig. 11. The rapid decrease in $Q_{\mathrm{o}_{2}}$ during the phase of growth is diminished with the beginning of riboflavin production and a further decrease to the minimal level occurs when production ceases.

The large amount of pyruvate in the medium also causes the rise of acetoin (Fig. 4). From the viewpoint of respiration the formation of acetoin represents a blind alley, but in connection with its possible role in the construction of the riboflavin molecule (Goodwin \& Treble, 1958; Goodwin, 1959) this formation might have great importance. This idea is supported by the disappearance of acetoin during the phase of production (Fig. 4). In other words, pyruvate (via acetaldehyde) is not only the substrate of the flavin enzyme but also the building material (via acetoin) for the construction of its prosthetic group. This hypothesis also explains the fact that acetate inhibits riboflavin biosynthesis but not growth on glucose medium (Brown et al. 1955). Acetate is the product of the reaction catalysed by the flavin enzyme and may act as a repressor of the synthesis of this enzyme or as a source of energy for which no new enzyme is necessary when this product is added exogenously. When comparing this interpretation of physiological mechanism of riboflavin production by Eremothecium ashbyi with the situation in Ashbya gossypii (Mickelson, 1950) it seems that the physiological mechanisms of riboflavin production by both organisms are very similar, with the exception that ethanol plays the role in $A$. gossypii which pyruvate plays in $E$. ashbyi.

The interchange of a cytochrome type of terminal respiration with a flavoprotein one, as a result of changes in environmental conditions, is not unknown in microorganisms. Nicholas (1956), with a mutant of Neurospora crassa which required riboflavin, found that when riboflavin deficiency occurred the activity of cytochrome oxidase increased to $140 \%$ and the activity of nitrate reductase and nitrite reductase decreased to $10 \%$ as compared with the control. At the same time the activity of catalase was decreased to $80 \%$ of the control. Lenhoff, Nicholas \& Kaplan (1956) found that in Pseudomonas fluorescens iron deficiency caused an increase in the activity of flavin enzymes and a decrease in the activity of cytochrome system.

I wish to thank Dr J. Stárka for his interest and all members of the Dept. of Microbiology for valuable help and advice, also Dr K. McQuillen for his help with the manuscript. 


\section{REFERENCES}

Ashwell, G. (1957). In Methods of Enzymology, vol. 3, p. 85. Ed. by S. R. Colowick \& N. O. Kaplan. New York: Academic Press Inc.

Avi-Dor, Y. \& Yaniv, H. (1952). The activity of catalase in Pasteurella tularensis. J. Bact. 63, 751.

Boyd, W. L. \& Lichstein, H. C. (1953). Effect of carbohydrates on aspartic acid deaminase activity of bacteria. Proc. Soc. exp. Biol., N.Y. 82, 45.

Brown, E. G., Goodwin, T. W. \& Jones, O. T. G. (1958). Studies on the biosynthesis of riboflavin. 4. Purine metabolism and riboflavin synthesis in Eremothecium ashbyi. Biochem. J. 68, 40.

Brown, E. G., Goodwin, T. W. \& Pendlington, S. (1955). Studies on the biosynthesis of riboflavin. 2. Further observations on nitrogen metabolism and flavinogenesis in Eremothecium ashbyi. Biochem. J. 61, 37.

Brown, F. \& Hall, L. P. (1950). Separation of carboxylate ions on the paper chromatogram. Nature, Lond. 166, 66.

Cavaluini, D. \& Frontali, N. (1954). Quantitative determination of keto-acids by paper partition chromatography. Biochim. biophys. Acta, 13, 439.

Dikanskaya, E. M. (1953). Issledovaniya po fiziologii pitaniya Eremothecium ashbyi. Microbiology, Moscoz, 22, 256.

Dikanskaya, E. M. (1954). Obrazovanie riboflavina mikroskopitsheskim gribom Eremothecium ashbyi. Trud. Inst. Mikrobiol. Akad. Nauk. 3, 35.

Dulaney, E. L. \& GruTter, F. H. (1950). The nutritional requirements of Eremothecium ashbyi. Guill. Mycologia, 42, 717 .

Friedeman, T. E. (1957). In Methods of Enzymology, vol. 3, p. 414. Ed. by S. R. Colowick \& N. O. Kaplan. New York: Academic Press Inc.

Goodwin, T. W. (1959). Production and biosynthesis of riboflavin in microorganisms. In Progress in Industrial Microbiology, vol. 1, p. 138. Ed. D. J. D. Hockenhull. London: Heywood Co.

Goodwin, T. W. \& Honton, A. A. (1960). Studies in flavinogenesis. 6. The role of threonine in riboflavin biosynthesis in Eremothecium ashbyi. Biochem. J. 75, 53.

Goodwin, T. W. \& Jones, O. T. G. (1956). Studies on the biosynthesis of riboflavin. 3. The utilization of ${ }^{14} \mathrm{C}$-labelled serine for riboflavin biosynthesis by Eremothecium ashbyi. Biochem. J. 64, 9.

Goodwin, T. W. \& Pendlington, S. (1954). Riboflavin in Eremothecium ashbyi. Nitrogen metabolism and flavinogenesis in Eremothecium ashbyi. Biochem. J. 57, 631.

Goodwin, T. W. \& Treble, D. H. (1958). The incorporation of ${ }^{-14} \mathrm{C} /$ acetylmethylcarbinol (acetoin) into ring $\mathbf{A}$ of riboflavin by Eremothecium ashbyi; a new route for the biosynthesis of an aromatic ring. Biochem. $J .70,14 \mathrm{P}$.

Hickey, R. J. (1953). Some nutritional requirements for biosynthesis of riboflavin by Eremothecium ashbyi. J. Bact. 66, 27.

Holló, J., Szamel, J., Nyeste, L. \& Tegerdy, R. (1956). Recherches sur la production de riboflavin a partir de residus agricoles. Industr. agric. aliment. Paris, 73, 519.

KAPRÁLEK, F. (1957). Zákonitosti v prủběhu submersní kultivace Eremothecium ashbyi. Preslia, 29, 113.

Katagiri, H. \& Imai, K. (1961). Mechanism of biosynthesis of riboflavin and its compounds. Abstr. 5th int. Congr. Biochem. 14.49.

KLungøsyr, L. (1954). The biosynthesis of riboflavin in Eremothecium ashbyi. Acta chem. scand. 8, 1292.

Kráml, A. \& Szabó, A. (1956). Die Wirkung von Redoxsystemen auf den Stoffwechsel von Mikroorganismen. 4. Veränderung der Riboflavinproduktion in geschüttelten Kulturen von Eremothecium ashbyi. Acta biol. Acad. sci. hung. 6, 197.

Krampitz, L. O. (1957). In Methods of Enzymology, vol. 3, p. 278. Ed. by S. R. Colowick \& N. O. Kaplan. New York: Academic Press Inc.

Lenhoff, H. M., Nicholas, D. J. D. \& Kaplan, N. O. (1956). Effects of oxygen, iron and molybdenum on routes of electrontransfer in Pseudomones fuorescens. J. biol. Chem. 220, 983. 
Lowry, H. O., Rosebrough, N. J., Farr, A. L. \& Randall, R. J. (1951). Protein measurement with the Folin phenol reagent. J. biol. Chem. 193, 265.

MacLaren, J. A. (1952). The effects of certain purines and pyrimidines upon the production of riboflavin by Eremothecium ashbyi. J. Bact. 63, 233.

McNuTT, W. S. (1954). The direct contribution of adenine to the biogenesis of riboflavin by Eremothecium ashbyi. J. biol. Chem. 210, 511.

Mickelson, M. N. (1950). The metabolism of glucose by Ashbya gossypii. J. Bact. 59, 659.

Nicholas, D. J. D. (1956). Trace metal requirements and some enzyme systems in a riboflavine-requiring mutant of Neurospora crassa. J. gen. Microbiol. 15, 470.

Pfeifer, V. F., Tanner, F. W. \& Traufler, D. H. (1950). Riboflavin by fermentation with Ashbya gossypii. Indust. Engn Chem. (Industr.), 42, 1776.

Plaut, G. W. E. (1954a). Biosynthesis of riboflavin. 1. Incorporation of C14-labelled compounds into rings $\mathrm{B}$ and $\mathrm{C}$. J. biol. Chem. 208, 513.

PlaUt, G. W. E. (1954b). Biosynthesis of riboflavin. 2. Incorporation of $\mathrm{C}^{14}$-labelled compounds into ring A. J. biol. Chem. 211, 111.

Schneider, W. C. \& Potter, V. R. (1943). The assay of animal tissues for respiratory enzymes. 2. Succinic dehydrogenase and cytochrome oxidase. J. biol. Chem. 149, 217.

Schopfer, W. H. (1944). La biotin, l'aneurin et le mésoinositol, facteurs de croissance pour Eremothecium ashbyi Guill. La biosynthèse de la flavine. Helv. chim. Acta, 27, 1017.

Shimizu, S., Ohara, S. \& Minoura, K. (1952). Riboflavin production by Eremothecium ashbyi. 32. Form of flavin produced during cultivation. J. ferment. Tech. Japan, 30, 13. Reported in Chem. Abst. 48, 3449d.

StÁ RKA, J. (1957). Properties of Eremothecium ashbyi strain-producing riboflavin. J.gen. Microbiol. 17, iv.

Sumner, J. B. (1941). The chemical nature of catalase. Advance Enzymol. 1, 163.

Yagi, K., Matsuoka, Y., Kuyama, S. \& TAda, M. (1956). Preparation of flavin adenine dinucleotide from Eremothecium ashbyi. J. Biochem., (Tokyo), 43, 93.

YAw, K. E. (1952). Production of riboflavin by Eremothecium ashbyi grown in a synthetic medium. Mycologia, 44, 307. 